\title{
The Earnings Management Strategy of List Companies in Pearl River Delta Region of China Based on Complex Network Theory
}

\author{
Run-Hua Zhao ${ }^{(D,}{ }^{1}$ Jie Cheng, ${ }^{2}$ and Nai-Ru $\mathrm{Xu}^{3}$ \\ ${ }^{1}$ The School of Finance and Accounting, Anhui Xinhua University, Hefei 230077, China \\ ${ }^{2}$ The School of International Education, Anhui Xinhua University, Hefei 230077, China \\ ${ }^{3}$ The School of Business, Anhui Xinhua University, Hefei 230077, China \\ Correspondence should be addressed to Run-Hua Zhao; zhaorunhua@axhu.edu.cn
}

Received 19 October 2020; Revised 2 November 2020; Accepted 25 November 2020; Published 10 December 2020

Academic Editor: M. Irfan Uddin

Copyright (c) 2020 Run-Hua Zhao et al. This is an open access article distributed under the Creative Commons Attribution License, which permits unrestricted use, distribution, and reproduction in any medium, provided the original work is properly cited.

This paper aims to detect the methods of earnings management in Pearl River Delta region of China. The data were selected based on the list companies of Pearl River Delta region from 2008 to 2019 and the balanced panel analysis was adopted to pursue the results. After the random effect analysis, this study reaches the conclusion that downward earnings is through total assets, the difference between sales and receivables, fixed assets, and sales and upward earnings is mainly through the changes of sales by the companies in Pearl River Delta region of China.

\section{Introduction}

Many studies have suggested that earnings management (EM) in accounting practice is adopted by companies around the world. The EM is actually a "disclosure management" in which corporate managers purposefully control the external financial reporting process to obtain certain private benefits [1]. The earnings management of this paper prefers to operating through violating the accounting principles and accounting estimations by corporate managers for the sake of meeting the desires of the personnel and the company. EM is the kind of accounting practice that not only distorts the financial health of the companies but also has a negative economic consequence to the corresponding accounting information users. Therefore, this paper pays close attention to the EM to prevent the misconduct and upgrades the quality of accounting information.

Many elements influence EM. The culture incrementally impacts accounting decisions beyond the effect of the accounting regime [2]. The way how the time encode of languages is significantly associated with earnings management [3]. Earnings management has a significant effect on incentives to reduce expense stickiness [4]. The executive compensation can lead to the implementation of REM, and the improvement of structural power of senior executives will significantly curb the REM based on the compensation of senior executives [5]. The material weakness in the internal control leads management to more likely employ real earnings management [6].

The Pearl River Delta (PRD) region, one of the prospective areas of China, is located in the south of China and has a special tradition, an identical subculture, a different language, and other peculiarity aspects. Too many differences exist between PRD region and the other parts of China, and the differences have led to different accounting practices. This paper aims to determine the EM strategy in the PRD region employed by the companies.

The rest of the papers are organized as follows. Section 2 reviews the related research backgrounds. Section 3 briefly introduces about PRD region. Section 4 employs a research approach. Finally, Section 5 provides results and suggestions.

\section{Literature Review}

Earnings management is one of the financial topics drawing many scholars' attention all over the world [7]. 
Earnings management can be classified in the following ways.

Firstly, depending on various targets of earnings management, the manipulation of earnings may be via positive or negative methods. The positive earnings management means uplifting the performances of the entity during a certain accounting period, cutting the expense, speeding the sales, and lessening the depreciation and amortization of longterm assets, which are the strategies often used in this kind. On the contrary, the negative earnings management usually use the methods such as delaying the sales of operation, uplifting the expense, accelerating the depreciation and amortization of long-term assets, and so on [8,9].

Secondly, according to the will of the manager, the earnings management consists of discretion and nondiscretion strategies. The discretion methods involve manipulating the earnings upward or downward to the existing transaction and events by the will of the manager, and it includes the decisions depending on the economic environment, the salary incentive, and other pressures; it is the question of "more or less," and we name it AEM [10]. The nondiscretion methods include recognition of having the identical transaction and events or not, also depending on the will of management; it is the question of "have or not," and we could call this kind of earnings management as REM [11]. Nowadays, as the inspection becomes crucial, more and more managers would like to shift the AEM toward the REM to avoid the inspection of the governance and professionals [12].

\section{PRD Region}

The Pearl River Delta region, as one of the flourishing districts, is located in the south-central Guangdong province of China, facing Southeast Asia across the sea. The Pearl River Delta region belongs to the south subtropical region. The climate is warm and humid all year round, with fertile soil, flat terrain, and criss-crossing rivers. Guangzhou, the central city of the Pearl River Delta region, has been the political, economic, and cultural center of Guangdong and Lingnan region for a long time. Lingnan culture is popular, and people have the spirit of change. About half of the gross national product of the Pearl River Delta is achieved through international trades. Many enterprises supply most of their products to the international market. The export-oriented economy is the basic way of development in the Pearl River Delta region. Meanwhile, the region has the advantage of being close to Hong Kong and Macao and facing Southeast Asia. It has the advantage of being home to overseas and has more private enterprises. The advantage of fine seaports, coupled with the preferential policies by the state, makes it a land to attract investment across the world. This district has been drawing the attention of scholars all over the world.

\section{Data and Methodology}

4.1. The Source of Data. The data of this paper were selected from the CSMAR's database and confined to the Pearl River Delta region. Because the economic situation was regular from the year 2008 to 2019, we choose this period to perform research in order to obtain a sound result. The data from national stock exchange were confined to the list companies because the management of this kind showed better condition. At first, 4737 year-company data were obtained through rehearsal, and 1815 year-company data were filtered. At last, 165 list companies consisting of private, stateowned, FDI, and other kinds of companies were selected as a balanced panel.

4.2. Methodology. After filtering some unbalanced data, the balanced panel data were obtained. After the Hausman test, this paper adopts the random effect method to complete this research to find the best use of the advantage of the panel model.

4.2.1. AEM Proxy. AEM was first introduced by Kothari et al. [11], and it was used to inspect abnormal accrual. Kothari et al. estimated an equation having the time series for each year. Following Kothari et al.'s equation, the modified Jones model for computing abnormal accrual is as follows [13]:

$$
\frac{\mathrm{TA}_{i, t}}{A_{i, t-1}}=\frac{\left(\alpha_{1 i, t}+\alpha_{2 i, t} 1\right)}{A_{i, t-1}}+\frac{\alpha_{3 i, t}\left(\Delta \mathrm{SALE}_{i, t}-\mathrm{REC}_{i, t}\right)}{A_{i, t-1}}+\frac{\alpha_{4 i, t} \mathrm{PPE}_{i, t}}{A_{i, t-1}}+\frac{\alpha_{5 i, t} \mathrm{NI}_{i, t}}{A_{i, t-1}}+\varepsilon_{i, t}
$$

where $i$ and $t$ stand for firm and year, respectively. $\mathrm{TA}_{i, t}$ stands for the total accrual for firm $i$ in year $t . \Delta \mathrm{SALE}_{i, t}$ stands for a change in net sales for firm $i$ in year $t . \Delta \mathrm{REC}_{i, t}$ stands for a change in account receivables for firm $i$ in year $t$. $\mathrm{PPE}_{i, t}$ stands for the net property, plant, and equipment for firm $i$ in year $t$. $\mathrm{NI}_{i, t}$ stands for the net income for firm $i$ in year $t$. $A_{i, t}$ stands for total assets for firm $i$ in year $t$. $\varepsilon$ is an error item and stands for the discretionary of the accrual or abnormal accrual (AEM) for an entity $i$ in year $t$.
4.2.2. REM Proxy. A proxy of REM employed by [1] detects abnormal CFO. CFO was estimated through regressing data of the balanced panel. This estimation evaluated the whole time series for each year according to Kothari et al. Therefore, the model for calculating abnormal CFO is shown below [14]:

$$
\frac{\mathrm{CFO}_{i, t}}{A_{i, t-1}}=\frac{\left(\beta_{1 i, t}+\beta_{2 i, t} 1\right)}{A_{i, t-1}}+\frac{\beta_{3 i, t} \operatorname{SALE}_{i, t}}{A_{i, t-1}}+\frac{\beta_{4 i, t} \Delta \mathrm{SALE}_{i, t}}{A_{i, t-1}}+\varepsilon_{i, t} \text {, }
$$


where $i$ and $t$ stands for firm and year. $\mathrm{CFO}_{i, t}$ stands for the cash flow from operation for firm $i$ in year $t$. SALE $_{i, t}$ stands for the net sales for firm $i$ in year $t . \Delta \mathrm{SALE}_{i, t}$ stands for a change in net sales for firm $i$ in year $t . A_{i, t}$ stands for the total resources for firm $i$ in year $t$, and $\varepsilon$ is the error term and stands for the abnormal CFO (REM) for entity $i$ in year $t$.

4.2.3. EM Proxy. The managers prefer the REM because the REM did not obviously lead to violation of the GAAP. Only after the prohibition is strict or the environment is not suitable, the manager will shift toward the AEM. Therefore, the AEM and REM are the two instruments the manager often used at the same time. This paper puts AEM and REM together to analyze fin order to obtain the integrity look of earnings management [15]. From (1) and (2), we have the following equation:

$$
\begin{aligned}
\mathrm{EM}= & \mathrm{AEM}+\mathrm{REM} \\
= & \frac{\mathrm{TA}_{i, t}}{A_{i, t-1}}+\frac{\mathrm{CFO}_{i, t}}{A_{i, t-1}} \\
= & \frac{\left(\alpha_{1 i, t}+\alpha_{2 i, t} 1\right)}{A_{i, t-1}}+\frac{\alpha_{3 i, t}\left(\Delta \mathrm{SALE}_{i, t}-\mathrm{REC}_{i, t}\right)}{A_{i, t-1}} \\
& +\frac{\alpha_{4 i, t} \mathrm{PPE}_{i, t}}{A_{i, t-1}}+\frac{\alpha_{5 i, t} \mathrm{NI}_{i, t}}{A_{i, t-1}} \\
& +\frac{\beta_{1 i, t}+\beta_{2 i, t} 1}{A_{i, t-1}}+\frac{\beta_{3 i, t} \mathrm{SALE}_{i, t}}{A_{i, t-1}}+\frac{\beta_{4 i, t} \Delta \mathrm{SALE}_{i, t}}{A_{i, t-1}}+\varepsilon_{i, t} .
\end{aligned}
$$

After rehearsal, we obtain

$$
\begin{aligned}
\mathrm{EM}= & \frac{\left(\alpha_{1 i, t}+\beta_{1 i, t}+\left(\alpha_{2 i, t}+\beta_{2 i, t}\right) 1\right)}{A_{i, t-1}}+\frac{\alpha_{3 i, t}\left(\Delta \mathrm{SALE}_{i, t}-\Delta \mathrm{REC}_{i, t}\right)}{A_{i, t-1}} \\
& +\frac{\alpha_{4 i, t} \mathrm{PPE}_{i, t}}{A_{i, t-1}}+\frac{\alpha_{5 i, t} \mathrm{NI}_{i, t}}{A_{i, t-1}}+\frac{\beta_{3 i, t} \operatorname{SALE}_{i, t}}{A_{i, t-1}}+\frac{\beta_{4 i, t} \operatorname{SALE}_{i, t}}{A_{i, t-1}}+\varepsilon_{i, t} .
\end{aligned}
$$

Because $\alpha_{1 i, t}$ and $\beta_{1 i, t}$ are constants, we use $\gamma$ to refer to them. So, the formula changes as

$$
\begin{aligned}
Y_{t}= & \gamma+\left(\alpha_{2 i, t}+\beta_{2 i, t}\right) x_{1}+\alpha_{3 i, t} x_{2}+\alpha_{4 i, t} x_{3}+\alpha_{5 i, t} x_{4} \\
& +\beta_{3 i, t} x_{5}+\beta_{4 i, t} x_{6}+\varepsilon_{i, t} .
\end{aligned}
$$

The variable explanations are shown in Table 1 [16].

4.3. Analysis. First, the variable summary is shown in Table 2.

Secondly, we adopt the unit root test to develop the further analysis. The results are in Table 3.

Although in the analysis, the test is passed, we can adopt the panel data for further analysis.

Finally, we adopt the Hausman test to determine the fixed effect or the random effect. The findings of the Hausman test are shown in Table 4 [1].
TABLE 1: Variable explanation.

\begin{tabular}{lc}
\hline Co & Company \\
\hline$Y_{t}$ & $\mathrm{EM}$ \\
$\gamma$ & $\alpha_{1 i, t}+\beta_{1 i, t}$ \\
$x_{1}$ & $1 / A_{i, t-1}$ \\
$x_{2}$ & $\left(\Delta \mathrm{SALE}_{i, t}-\Delta \mathrm{REC}_{i, t}\right) / A_{i, t-1}$ \\
$x_{3}$ & $\mathrm{PPE}_{i, t} / A_{i, t-1}$ \\
$x_{4}$ & $\mathrm{NI}_{i, t} / A_{i, t-1}$ \\
$x_{5}$ & $\mathrm{SALE}_{i, t} / A_{i, t-1}$ \\
$x_{6}$ & $\Delta \mathrm{SALE}_{i, t} / A_{i, t-1}$ \\
\hline
\end{tabular}

TABLE 2: Variable summary.

\begin{tabular}{ccccc}
\hline Obs & Mean & Std. dev. & Min & Max \\
\hline 1815 & 0.06445 & 0.32961 & -0.61052 & 12.040 \\
1815 & $5.79 e-10$ & $2.15 e-09$ & $6.54 e-13$ & $5.28 e-08$ \\
1815 & 0.25897 & 6.4514 & -3.2560 & 263.90 \\
1815 & 0.24858 & 0.31462 & 0.00008 & 9.9485 \\
1815 & 0.06230 & 0.34764 & -0.61025 & 12.784 \\
1815 & 1.0077 & 9.7941 & 0.01100 & 406.97 \\
1815 & 0.36952 & 9.7370 & -3.2870 & 404.55 \\
\hline
\end{tabular}

Source: CSMAR's database

Because $p$ is 0.4676 , we think this panel belongs to a random model. We use the between-group estimator to analyze this. The results of between-group estimator are reflected in Table 5 .

\section{Results and Suggestions}

\subsection{Results}

5.1.1. Type 1: Downward Earnings Management. The result shows that $x_{1}, x_{2}, x_{3}$, and $x_{5}$ are downward earnings management elements.

$x_{1}$ stands for $1 /\left(A_{i, t-1}\right)$, which is $-5169880, x_{2}$ stands for $\left(\triangle \mathrm{SALE}_{i, t}-\triangle R E C_{i, t}\right) /\left(A_{i, t-1}\right)$, which is $-0.1718596, x_{3}$ stands for $\left(\mathrm{PPE}_{i, t} / A_{i, t-1}\right)$, which is -0.0035354 , and $x_{5}$ stands for $\operatorname{SALE}_{i, t} /\left(A_{i, t-1}\right)$, which is -0.0019389 . This means that the management of downward earnings can be done through assets, the difference between sales and receivables, fixed assets, and sales. This cluster is labelled as the downward group. Within this group, $x_{1}$ is the biggest one, and this shows that the asset tools are widely used by the management to manipulate the earnings downward along with the sales, the differences of sales, and fixed assets.

5.1.2. Type 2: Upward Earnings Management. $x_{4}$ and $x_{6}$ are upward earnings management tools because of positive values and so this cluster is labelled as the upward group. $x_{4}$ stands for $\mathrm{NI}_{i, t} /\left(A_{i, t-1}\right)$, which is 1.081116 , and $x_{6}$ stands for $\Delta \operatorname{SALE}_{i, t} /\left(A_{i, t-1}\right)$, which is 0.11197 . This means that they would like to manipulate earnings upward via net income and the changes of sales. 1.081116 is more than 0.11197 , and this gives us the information that the net income method is more often used than the change of sales for upward earnings. 
TABLE 3: Result of unit root.

\begin{tabular}{|c|c|c|c|c|c|c|}
\hline \multicolumn{5}{|l|}{$\begin{array}{l}\text { Number of obs }=1,815 \\
\text { R-sq: within }=0.9438 \\
\text { Between }=0.9202 \\
\text { Overall }=0.9415 \\
\text { Group variable: Co } \\
\text { Corr (u_i, } X)=0 \text { (assumed) }\end{array}$} & \multicolumn{2}{|c|}{$\begin{array}{c}\text { Number of groups }=16 \\
\text { Obs per group: } \min =11 \\
\text { Avg }=11.0 \\
\operatorname{Max}=11 \\
\text { Wald } \operatorname{chi}^{2}(6)=29087.44 \\
\text { Prob }>\operatorname{chi}^{2}=0.0000\end{array}$} \\
\hline$\overline{y_{t}}$ & Coef. & Std. err. & $Z$ & $P>z$ & (95\% col & interval) \\
\hline$x_{1}$ & -4649495 & 1069459 & -4.35 & 0.000 & -6745596 & -2553393 \\
\hline$x_{2}$ & 0.0012328 & 0.0048786 & 0.25 & 0.801 & -0.0083291 & 0.0107948 \\
\hline$x_{3}$ & -0.0105319 & 0.0086824 & -1.21 & 0.225 & -0.027549 & 0.0064853 \\
\hline$x_{4}$ & 0.8395955 & 0.0109845 & 76.43 & 0.000 & 0.8180663 & 0.8611246 \\
\hline$x_{5}^{4}$ & -0.0078637 & 0.0035245 & -2.23 & 0.026 & -0.0147715 & -0.0009559 \\
\hline$x_{6}$ & 0.0111806 & 0.0049028 & 2.28 & 0.023 & 0.0015713 & 0.0207899 \\
\hline _Cons & 0.0209265 & 0.0036572 & 5.72 & 0.000 & 0.0137585 & 0.0280945 \\
\hline sigma_u & 0 & & & & & \\
\hline sigma_e & 0.07777193 & & & & & \\
\hline Rho & 0 & (Fraction of variance due to $\mathrm{u}_{\mathrm{i}} \mathrm{i}$ ) & & & & \\
\hline
\end{tabular}

TABLE 4: The findings of Hausman test.

\begin{tabular}{lcccc}
\hline & $(B)$ & $(b-B)$ & \multicolumn{2}{c}{ Sqrt $($ diag $($ V_b - V_B $))$} \\
SE \\
\hline$x_{1}$ & FE & RE & Difference & 878663.8 \\
$x_{2}$ & -4011297 & -4649495 & 638197.9 & 0.0024575 \\
$x_{3}$ & 0.0166332 & 0.0012328 & 0.0154003 & 0.0156202 \\
$x_{4}$ & -0.0082575 & -0.0105319 & 0.0022744 & 0.004411 \\
$x_{5}$ & 0.8303778 & 0.8395955 & -0.0092176 & 0.0068185 \\
$x_{6}$ & -0.0031594 & -0.0078637 & 0.0047043 & 0.007662 \\
Cons & -0.0035012 & 0.0111806 & -0.0146818 & 0.0054629 \\
\hline
\end{tabular}

$b=$ consistent under $\mathrm{Ho}$ and $\mathrm{Ha}$, obtained from xtreg. $B=$ inconsistent under Ha, efficient under Ho, and obtained from. xtreg. Test. Ho: difference in coefficients being not systematic. $C_{i}^{2}(1)=(b-B)^{\prime}\left[\left(V_{-} b-V_{-} B\right)^{-1}\right](b-B)=0.53$. Prob $>c^{2} i^{2}=0.4676 ;\left(V \_b-V \_B\right)$ is not positive definite.

TABLE 5: The results of between-group estimator.

\begin{tabular}{|c|c|c|c|c|c|c|}
\hline Number of obs $=1,815$ & & & & & \multicolumn{2}{|c|}{ Number of groups $=165$} \\
\hline Group variable: Co, & & & & & \multicolumn{2}{|c|}{ R-sq: } \\
\hline Obs per group: & & & & & \multicolumn{2}{|c|}{$\min =11$} \\
\hline Within $=0.8802$ & & & & & \multicolumn{2}{|c|}{ Between $=0.9672$} \\
\hline $\operatorname{Avg}=11.0$ & & & & & \multicolumn{2}{|c|}{$\operatorname{Max}=11$} \\
\hline$F(6,158)=777.51$ & & & & & \multicolumn{2}{|c|}{ Overall $=0.8871$} \\
\hline $\mathrm{Sd}(\mathrm{u} i+\operatorname{avg}(\mathrm{e}$ i. $))=0.0188445$ & & & & & \multicolumn{2}{|c|}{ Prob $>F=0.0000$} \\
\hline$y_{t}$ & Coef. & Std. err. & $t$ & $P>|t|$ & \multicolumn{2}{|c|}{ (95\% conf. Interval) } \\
\hline$x_{1}$ & -5169880 & 2796931 & -1.85 & 0.066 & $-1.07 e+07$ & 354316.1 \\
\hline$x_{2}$ & -0.1718596 & 0.0124933 & -13.76 & 0.000 & -0.196535 & -0.1471842 \\
\hline$x_{3}$ & -0.0035354 & 0.007921 & -0.45 & 0.656 & -0.0191801 & 0.0121093 \\
\hline$x_{4}$ & 1.081116 & 0.0269564 & 40.11 & 0.000 & 1.027874 & 1.134357 \\
\hline$x_{5}$ & -0.0019389 & 0.0032112 & -0.60 & 0.547 & -0.0082813 & 0.0044035 \\
\hline$x_{6}$ & 0.11197 & 0.0085434 & 13.11 & 0.000 & 0.0950959 & 0.1288441 \\
\hline Cons & 0.0060512 & 0.0037794 & 1.60 & 0.111 & -0.0014135 & 0.0135159 \\
\hline
\end{tabular}

5.2. Suggestions. As auditors or analysts, when pursuing an analysis about a firm, to fully achieve the goal, we should pay close attention to the management of earnings.

First, we should know whether assets, the difference between sales and receivables, PPE assets, and sales are manipulated when the performance is downward, especially the asset management.
Second, if the earnings is upward, the attention of analysts should shift toward the net income and the changes of sales of the companies.

Last but not the least, the analysts should pay close attention to the strategies of sales delaying or speeding, as well as the discretionary expenditures, decreasing $R \& D$ expenses, and administrative expenses. 


\section{Data Availability}

The data used to support the findings of this study are included within the article.

\section{Conflicts of Interest}

The authors declare there are no conflicts of interest regarding the publication of this paper.

\section{Authors' Contributions}

All authors contributed to this paper equally.

\section{Acknowledgments}

This work was supported by the Key Project of the Special Foundation of Education Section of Anhui Province of China (SK2019A0731).

\section{References}

[1] N. Likitwongkajon and S. Sutthachai, "Colonialism influence on accounting practice in Asian countries regarding earnings management strategy classification," International Journal of Business and Society, vol. 20, no. 1, pp. 125-150, 2019.

[2] A. A. P. Paredes and C. Wheatley, "The influence of culture on real earnings management," International Journal of Emerging Markets, vol. 12, no. 1, pp. 38-57, 2017.

[3] J. Kim, Y. Kim, and J. Zhou, "Languages and earnings management," Journal of Accounting and Economics, vol. 63, no. 2-3, pp. 288-306, 2017.

[4] S. Xue and Y. Hong, "Earnings management, corporate governance and expense stickiness," China Journal of Accounting Research, vol. 9, no. 1, pp. 41-58, 2016.

[5] Yu Lei, Y. Dai, K. Zheng, and Y. Zhang, "Empirical research on the correlation between Real Earnings Management of state-owned enterprises and executive compensation---from the perspective of executive structural power," International Journal of Financial Engineering, vol. 6, no. 1, p. 1950008, 2019.

[6] T. Jarvinen and E.-R. Myllymaki, "Real earnings management before and after reporting SOX 404 material weaknesses," Accounting Horizon, vol. 30, no. 1, pp. 119-141, 2016.

[7] P. M. Dechow and D. J. Skinner, "Earnings management: reconciling the views of accounting academics, practitioners, and regulators," Accounting Horizons, vol. 14, no. 2, pp. 235-250, 2000.

[8] J. R. Graham, C. R. Harvey, and S. Rajgopal, "The economic implications of corporate financial reporting," Journal of Accounting and Economics, vol. 40, no. 1-3, pp. 3-73, 2005.

[9] D. A. Cohen and P. Zarowin, "Accruals-based and real earnings management activities around seasoned equity offerings," Journal of Accounting and Economics, vol. 50, no. 1, pp. 2-19, 2020.

[10] W. Wongsunwai, "The effect of external monitoring on accruals based and real earnings management: evidence from venture backed initial public offerings," Contemporary Accounting Research, vol. 30, no. 1, pp. 296-324, 2013.

[11] S. P. Kothari, N. Mizik, and S. Roychowdhury, "Managing for the moment: the role of real activity versus accruals earnings management in SEO valuation," SSRN Electronic Journal, vol. 91, no. 2, 2012.
[12] P. M. Healy and J. M. Wahlen, "A review of the earnings management literature and its implications for standard setting," Accounting Horizons, vol. 13, no. 4, pp. 365-383, 1999.

[13] C. Leuz, D. Nanda, and P. D. Wysocki, "Earnings management and investor protection: an international comparison," Journal of Financial Economics, vol. 69, no. 3, pp. 505-527, 2003.

[14] P. M. Dechow, R. G. Sloan, and A. P. Sweeney, "Detecting earnings management," The Accounting Review, vol. 70, no. 2, pp. 193-225, 1995, http://www.jstor.org/stable/248303.

[15] K. A. Gunny, “The relation between earnings management using real activities manipulation and future performance: evidence from meeting earnings benchmarks," Contemporary Accounting Research, vol. 27, no. 3, pp. 855-888, 2010.

[16] W. A. W. Ismail, K. A. Kamarudin, T. Van Zijl, and K. Dunstan, "Earnings quality and the adoption of IFRS-based accounting standards: evidence from an emerging market," Asian Review of Accounting, vol. 21, no. 1, pp. 53-73, 2013. 